\title{
Aerosol promotes peroxyacetyl nitrate (PAN) formation during winter in the North
}

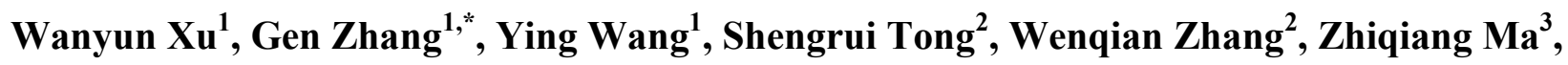
5 Weili Lin ${ }^{4}$, Ye Kuang ${ }^{5,6}$, Liyuan Yin ${ }^{1, a}$, Xiaobin $X^{1}{ }^{1, *}$

${ }^{1}$ State Key Laboratory of Severe Weather \& Key Laboratory for Atmospheric Chemistry of

CMA, Institute of Atmospheric Composition, Chinese Academy of Meteorological Sciences, $8 \quad$ Beijing, 100081, China

$9 \quad{ }^{2}$ Institute of Chemistry, Chinese Academy of Sciences, Beijing, 100190, China

$10{ }^{3}$ Institute of Urban Meteorology, China Meteorological Administration, Beijing 100089, China

$11{ }^{4}$ College of Life and Environmental Sciences, Minzu University of China, Beijing, 100081, 12 China

$13{ }^{5}$ Institute for Environmental and Climate Research, Jinan University, Guangzhou, China.

$14{ }^{6}$ Guangdong-Hongkong-Macau Joint Laboratory of Collaborative Innovation for Environmental 15 Quality, Guangzhou, China.

$16{ }^{a}$ Now at School of Physics, Peking University, Beijing 100871, China 17

18 Corresponding authors: Gen Zhang (zhanggen@cma.gov.cn) and Xiaobin Xu 19 (xuxb01@163.com) 
Table of contents

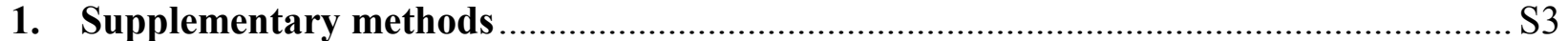

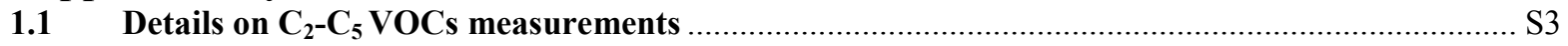

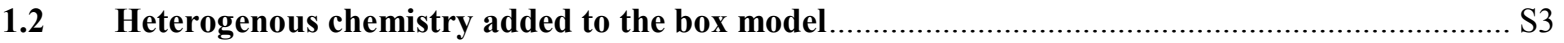

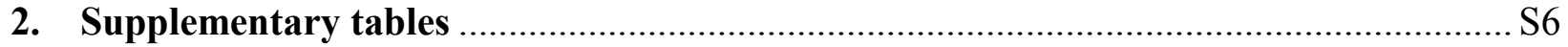

Table S1. Reactions associated with PAN formation and according reaction rates .................. S6

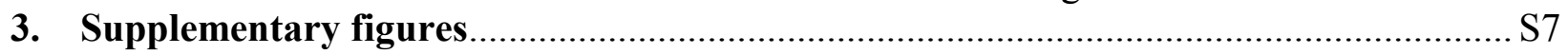

Figure S1. Multipoint calibrations of a) $\mathrm{C}_{3} \mathrm{H}_{6} \mathrm{O}$ and b) $\mathrm{C}_{6} \mathrm{H}_{6}$ and fitted sensitivity curve during the two calibrations of PTR-ToF-MS.

Figure S2. Average distribution of a) $\mathrm{NO}_{2}$, b) $\mathrm{HCHO}$ and c) aerosol optical depth measured by OMI (Ozone Monitoring Instrument) during 2016.

Figure S3. Variation of PAN with $\mathrm{NO} / \mathrm{NO}_{2}$ ratio and OVOCs during nighttime under a)

southerly and b) northerly winds.

Figure S4 Variation of the relative contribution of acetaldehyde, methyl glyoxal, biacetyl and other OVOCs to the formation of PA radicals with the daytime PAN formation rate

Figure S5 Variation of PAN with $\mathrm{NO} / \mathrm{NO}_{2}$ ratio and a) acetaldehyde, b) acetone, c)

MACR+MVK and d) biacetyl during the entire campaign.

Figure S6. Correlation between $\mathrm{PM}_{2.5}$ and NO/NO 2 during Nov. 2016-Jan. 2017 observed at the Chinese Academy of Meteorological Sciences, Beijing, China.

Figure S7. Correlations between nighttime $\mathrm{HONO}, \mathrm{NH}_{3}$ and $\mathrm{PM}_{2.5}$ during 10 Nov.-24 Dec. 2016 in urban Beijing.

Figure S8. Variation of acetaldehyde, acetone, MACR + MVK and biacetyl conversion rates with $\mathrm{PM}_{2.5}$ concentrations during $\mathrm{P} 2$.

Figure S9. Correlation between BTEX measured by PTR-TOF-MS and propene measured by an GC-FID instrument measured during 19 Jan. to 11 Feb. 2017 (Supplementary methods Sect1.1) 


\section{Supplementary methods}

75 $76 \quad 1$

$77 \mathrm{HO}_{2} \stackrel{\mathrm{kHO}_{2}}{\longrightarrow}$ Aerosol, $\mathrm{kHO}_{2}=0.25 \times \gamma_{\mathrm{HO}_{2}} \times v_{\mathrm{HO}_{2}} \times S_{a}$, $78 \quad 1$ propene, could not be measured by the PTR-ToF-MS instrument. above 0.99 , indicating a good linear response.

\subsection{Heterogenous chemistry added to the box model} MCMv3.2:

$\mathrm{OH} \stackrel{\mathrm{kOH}}{\longrightarrow}$ Aerosol, $\mathrm{kOH}=0.25 \times \gamma_{\mathrm{OH}} \times v_{O H} \times S_{a}$,

\subsection{Details on $\mathrm{C}_{2}-\mathrm{C}_{5}$ VOCs measurements}

In the calculation of acetaldehyde conversion rate, one of its most important precursors,

However, $\mathrm{C}_{2}-\mathrm{C}_{5}$ VOC species were monitored using an online Syntech Spectras gas chromatography 955 (GC955) 811 analyzer at the Institute of Urban Meteorology (located $2.7 \mathrm{~km}$ southwest of the China Meteorological Administration) during 19 Jan to 11 Feb. 2017. $\mathrm{C}_{2}-\mathrm{C}_{5}$ hydrocarbons were pre-concentrated on a cooled trap, desorbed thermally, and separated on a DB-1 equivalent column $(30.0 \mathrm{~m} \times 0.32 \mathrm{~mm} \times 1.8 \mu \mathrm{m})$, after which they were analyzed by a photo ionization detector and a flame ionization detector in order to ensure high sensitivity and good identification. The online 811 system can measure VOC concentrations between the lower detection limit $(0.1 \mathrm{ppb})$ and $30 \mathrm{ppb}$ with a time resolution of $30 \mathrm{~min}$. Multipoint calibrations have been performed before and after the measurements using the US EPA Photochemical Assessment Monitoring Stations (PAMS) standards, revealing linear correlation coefficient

Since the GC measurements were not in the time range of our PAN and VOCs measurements, a correlation analysis was performed between PTR-ToF-MS measurements and GC955 measured propene (propene $_{\mathrm{GC}}$ ) concentrations, yielding a very good relationship between propene $_{\mathrm{GC}}$ and BTEX $\mathrm{PTR}$ (Fig. S5), with a linear slope of 1.55. Based on this relationship, propene in the calculations of acetaldehyde precursors was replaced by $1.55 \times \mathrm{BTEX}_{\mathrm{PTR}}$.

To investigate the impact of heterogeneous chemistry on PAN formation, the following mechanisms were added to the MCM-based box model beside those already existing in 
79 wherein $\gamma_{\mathrm{OH}}$ and $\gamma_{\mathrm{HO}_{2}}$ were both calculated as $\gamma=\left(\frac{1}{\alpha}+\frac{\left(0.75+0.286 \times K_{n}\right)}{K_{n} \times\left(K_{n}+1\right)}\right)^{-1} 1$. Here, $\alpha$ is the 80 accommodation coefficient $\left(\propto_{\mathrm{OH}}\right.$ and $\propto_{\mathrm{HO}_{2}}$ both assumed to be 0.2$)$ and $K_{n}$ is the Knudsen 81 number.

82

$\mathrm{NO}_{2} \stackrel{\mathrm{kNO}_{2, a 1}}{\longrightarrow}$ nitrate $+\mathrm{HONO}$,

$86 \mathrm{NO}_{2} \stackrel{\mathrm{kNO}_{2, g}}{\longrightarrow} \mathrm{HONO}, \mathrm{kHO}_{2}=0.25 \times \gamma_{\mathrm{NO}_{2, g}} \times v_{\mathrm{NO}_{2}} \times S_{g}$,

$k N O_{2, a 1}=0.25 \times \gamma_{N O_{2, a}} \times v_{N O_{2}} \times S_{a} \times\left(N_{3} / N_{3, a v g}\right)^{2}$,

88 nitrate $+h v \stackrel{j_{\text {nitrate }}}{\longrightarrow} \mathrm{HONO}, j_{\text {nitrate }}=0.5 \times j_{\mathrm{NO}_{2}}$

$90 \mathrm{~N}_{2} \mathrm{O}_{5} \stackrel{\mathrm{kN}_{2} \mathrm{O}_{5}}{\longrightarrow}(2-\phi)$ nitrate $+\phi \mathrm{ClNO} 2, \mathrm{kN}_{2} \mathrm{O}_{5}=0.25 \times \gamma_{\mathrm{NO}_{2, a}} \times v_{\mathrm{NO}_{2}} \times S_{a}, \phi=0.2$,

Here, $\gamma_{\mathrm{NO}_{2, a}}$ and $\gamma_{\mathrm{NO}_{2, g}}$ are the $\mathrm{NO}_{2}$ uptake coefficients on aerosol surface and ground surface and were assumed to be $10^{-6}$ and $10^{-7}$, respectively $\underline{4} . S_{g}$ is effective surface density of the ground and was assumed to be $0.001 \mathrm{~cm}^{-1} \underline{5} . S_{a}$ refers to the ambient aerosol surface area and was parameterized based on the following derivations: Assuming $\mathrm{PM}_{2.5}$ was measured at dry state, the dry state aerosol surface area concentration can be calculated as

$99 \quad S_{a, d r y}=6 \times \frac{P M_{2.5}}{\rho_{a} \times D_{a}}$

100 Here, $\rho_{a}$ is the aerosol density and is assumed to be $1.7 \mathrm{~g} \mathrm{~cm}^{-3}$

101 For aerosols larger than $100 \mathrm{~nm}$, their diameter hygroscopic growth factor can be approximated 102 as: $\underline{6} 7$

$103 G F(R H) \approx\left(1+\kappa \frac{R H}{100-R H}\right)^{1 / 3}$

104 Based on that, the aerosol surface area under ambient conditions can be approximated as:

$105 S_{a}=6 \times \frac{P M_{2.5}}{\rho_{a} \times D_{a}} \times\left(1+\kappa \frac{R H}{100-R H}\right)^{2 / 3}$ 
106 Although some studies observed HONO formation on aerosols proceed via heterogeneous 107 reactions of $\mathrm{NO}_{2}$ and $\mathrm{SO}_{2}, \underline{8}$ such a reaction revealed minor influences in field studies in the $108 \mathrm{NCP}, \underline{2}$ which is why only the $\mathrm{NH}_{3}$-promoted hydrolysis reaction is considered in this study.

109

110 


\section{Supplementary tables}

112 Table S1. Reactions associated with PAN formation and according reaction rates

113

\begin{tabular}{|c|c|c|c|}
\hline Reactions & $\begin{array}{c}\mathbf{k} \mathbf{2 9 8} \\
\mathrm{cm}^{3} \text { molecule }^{-1} \mathrm{~s}^{-1} \\
\end{array}$ & $\begin{array}{l}\mathbf{k}(\mathbf{T}) \text { or } \mathbf{k}(\mathbf{T},[\mathbf{M}])^{*} \\
\mathrm{~cm}^{3} \text { molecule }^{-1} \mathrm{~s}^{-1}\end{array}$ & Reference \\
\hline Acetaldehyde $+\mathrm{OH}$ & $1.5 \times 10^{-11}$ & $4.4 \times 10^{-12} \exp (365 / \mathrm{T})$ & $\underline{9}$ \\
\hline Acetone $+\mathrm{OH}$ & $1.8 \times 10^{-13}$ & $8.8 \times 10^{-12} \exp (-1320 / \mathrm{T})$ & $\underline{9}$ \\
\hline $\mathrm{MGLY}+\mathrm{OH}$ & $1.2 \times 10^{-11}$ & $1.83 \times 10^{-12} \exp (560 / \mathrm{T})$ & $\underline{10}$ \\
\hline $\begin{array}{l}\text { MACR }+\mathrm{OH} \ldots+\mathrm{NO} \\
\text { (branching ratio of } 0.45 \text { for } \\
\text { aldehydic abstraction) }\end{array}$ & $2.9 \times 10^{-11}$ & $8.0 \times 10^{-12} \exp (380 / \mathrm{T})$ & $\underline{9}$ \\
\hline MVK & $2.0 \times 10^{-11}$ & $2.6 \times 10^{-12} \exp (610 / \mathrm{T})$ & $\underline{9}$ \\
\hline Biacetyl $+\mathrm{h} v$ & $\begin{array}{l}j_{\text {Biacety }} \approx 3.64 \% \times j_{N O 2} \\
j_{\text {Biacetyl,max }}=1.8 \times 10^{-4}\end{array}$ & $\begin{array}{l}\text { estimated for wintertime } \\
\mathrm{k}_{0}=2.7 \times 10^{-28}(\mathrm{~T} / 300)^{-7.1}\end{array}$ & $\underline{10}$ \\
\hline $\mathrm{PA}+\mathrm{NO}_{2}\left(\mathrm{k}_{2}\right.$ in manuscript $)$ & $1.0 \times 10^{-11}$ & $\begin{array}{l}\mathrm{k}_{\infty}=1.2 \times 10^{-11}(\mathrm{~T} / 300)^{-0.9} \\
\mathrm{~F}_{\text {cent }}=0.3 \\
\mathrm{~N}=1\end{array}$ & $\underline{10}$ \\
\hline $\begin{array}{l}\text { PA thermal dissociation }\left(\mathrm{k}_{3}\right. \\
\text { in manuscript) }\end{array}$ & $4.6 \times 10^{-4}$ & $\begin{array}{l}\mathrm{k}_{0}=4.9 \times 10^{-3} \exp (-12100 / \mathrm{T}) \\
\mathrm{k}_{\infty}=4.0 \times 10^{16} \exp (-13600 / \mathrm{T}) \\
\mathrm{F}_{\text {cent }}=0.3 \\
\mathrm{~N}=1.41\end{array}$ & $\underline{10}$ \\
\hline $\mathrm{PA}+\mathrm{NO}\left(\mathrm{k}_{4}\right.$ in manuscript $)$ & $2.0 \times 10^{-11}$ & $8.1 \times 10^{-12} \exp (270 / T)$ & $\underline{10}$ \\
\hline
\end{tabular}




\section{Supplementary figures}
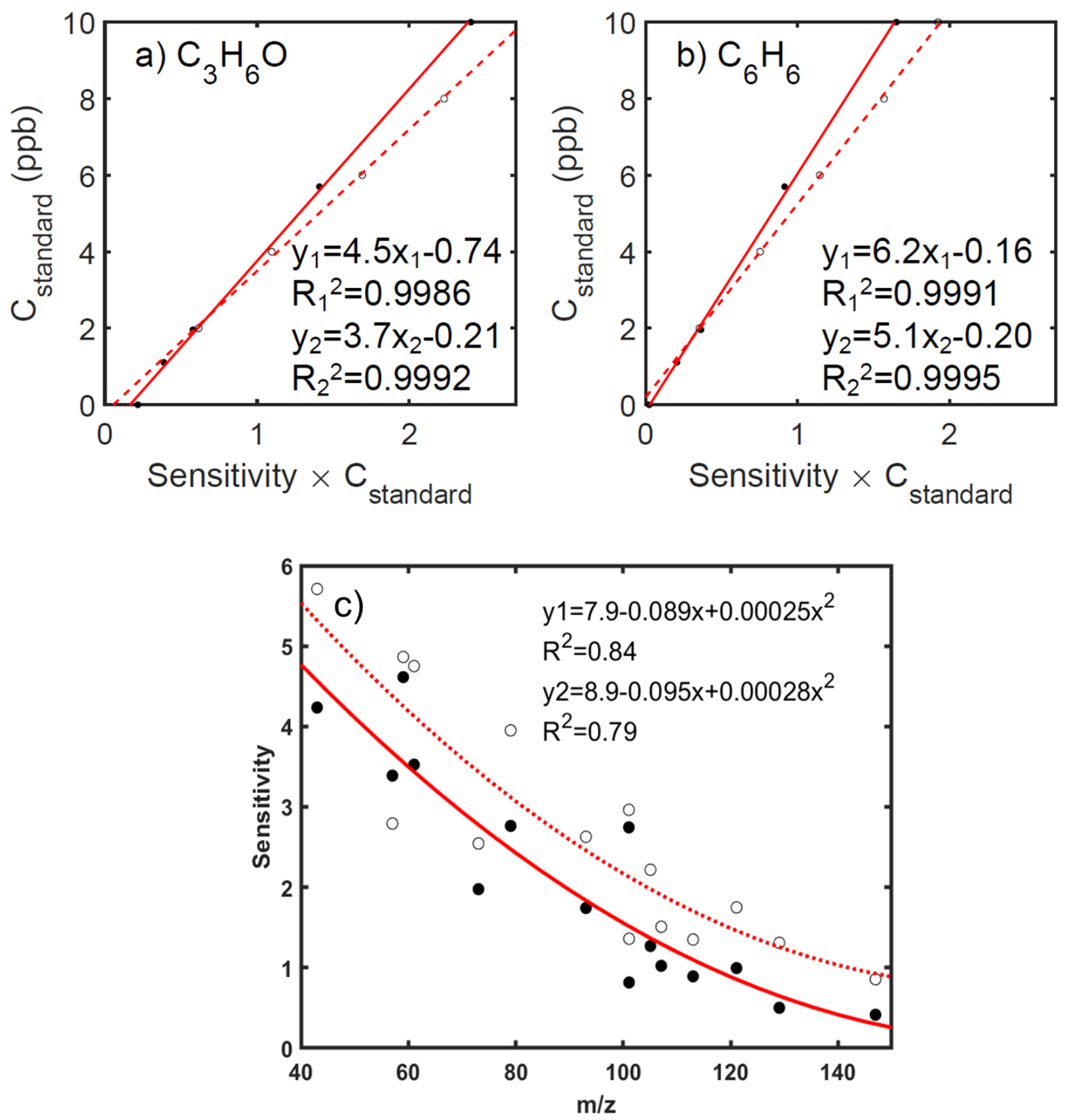

117

118

119

120

Figure S1. Multipoint calibrations of
the two calibrations of PTR-ToF-MS. 
121

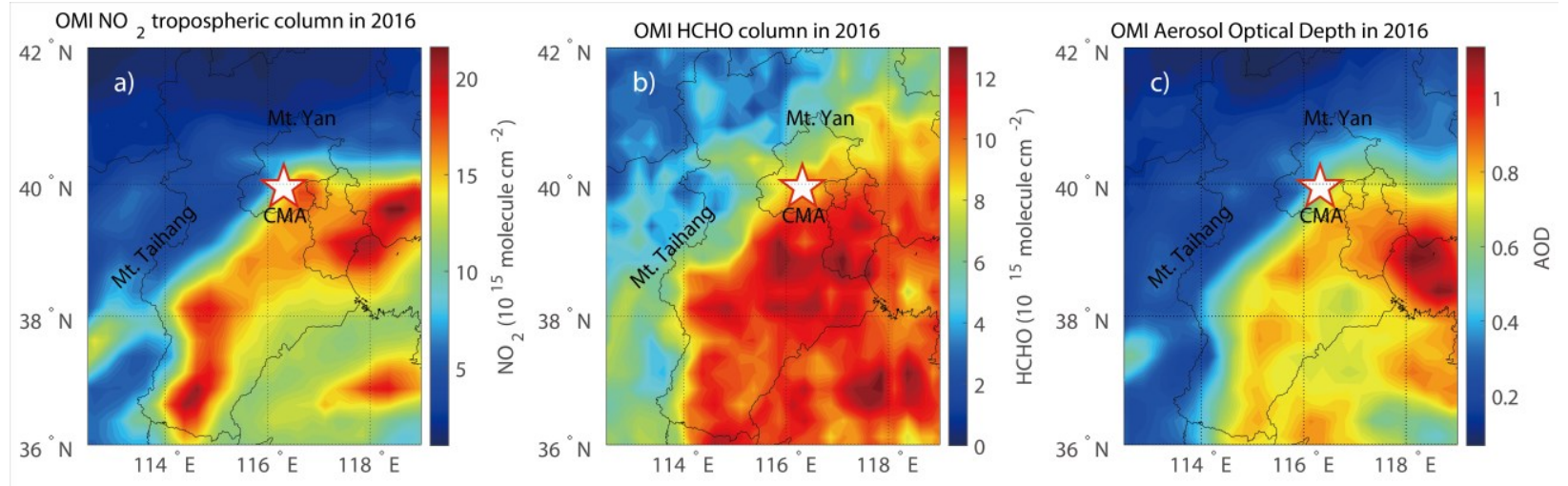

Figure S2. Average distribution of a) $\mathrm{NO}_{2}$, b) $\mathrm{HCHO}$ and c) aerosol optical depth measured by 124 OMI (Ozone Monitoring Instrument) during 2016.

125 

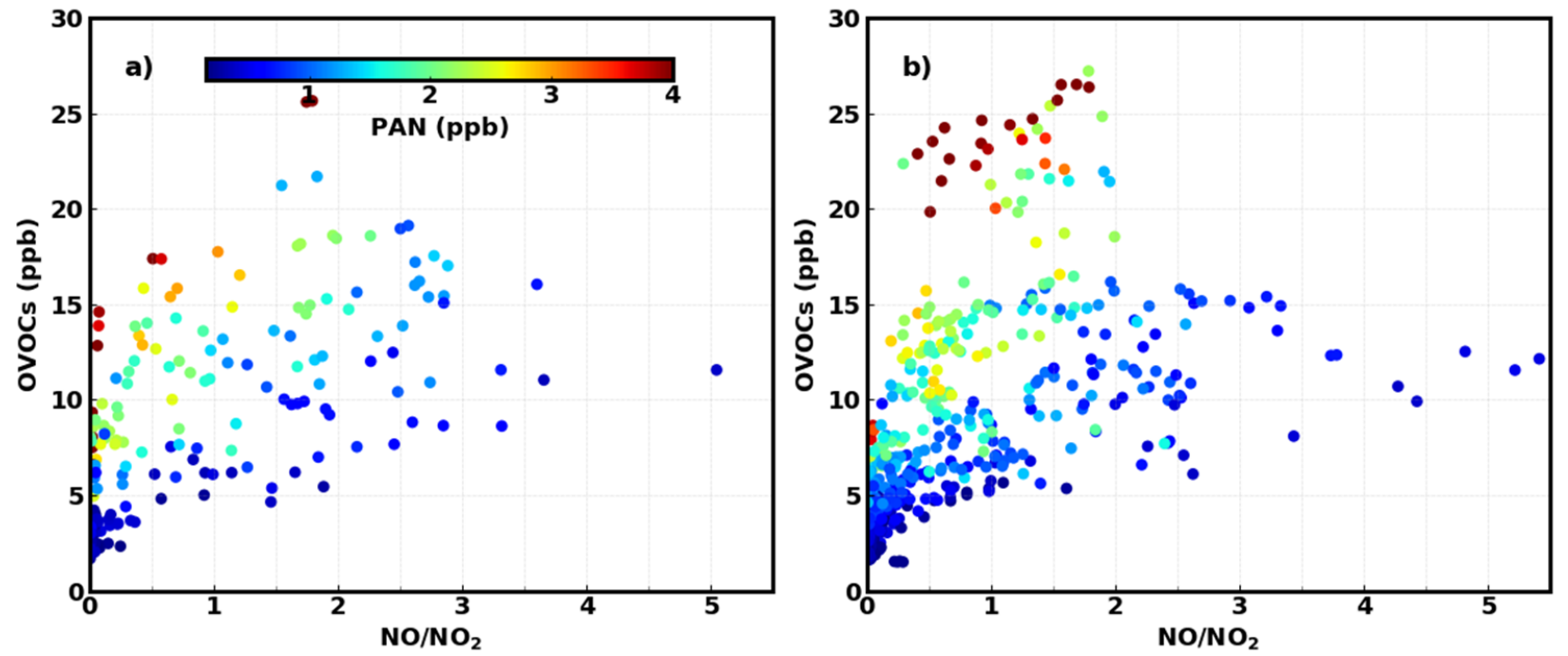

127

Figure S3. Variation of $\mathrm{PAN}$ with $\mathrm{NO} / \mathrm{NO}_{2}$ ratio and OVOCs during nighttime under a) southerly and b) northerly winds.

129 


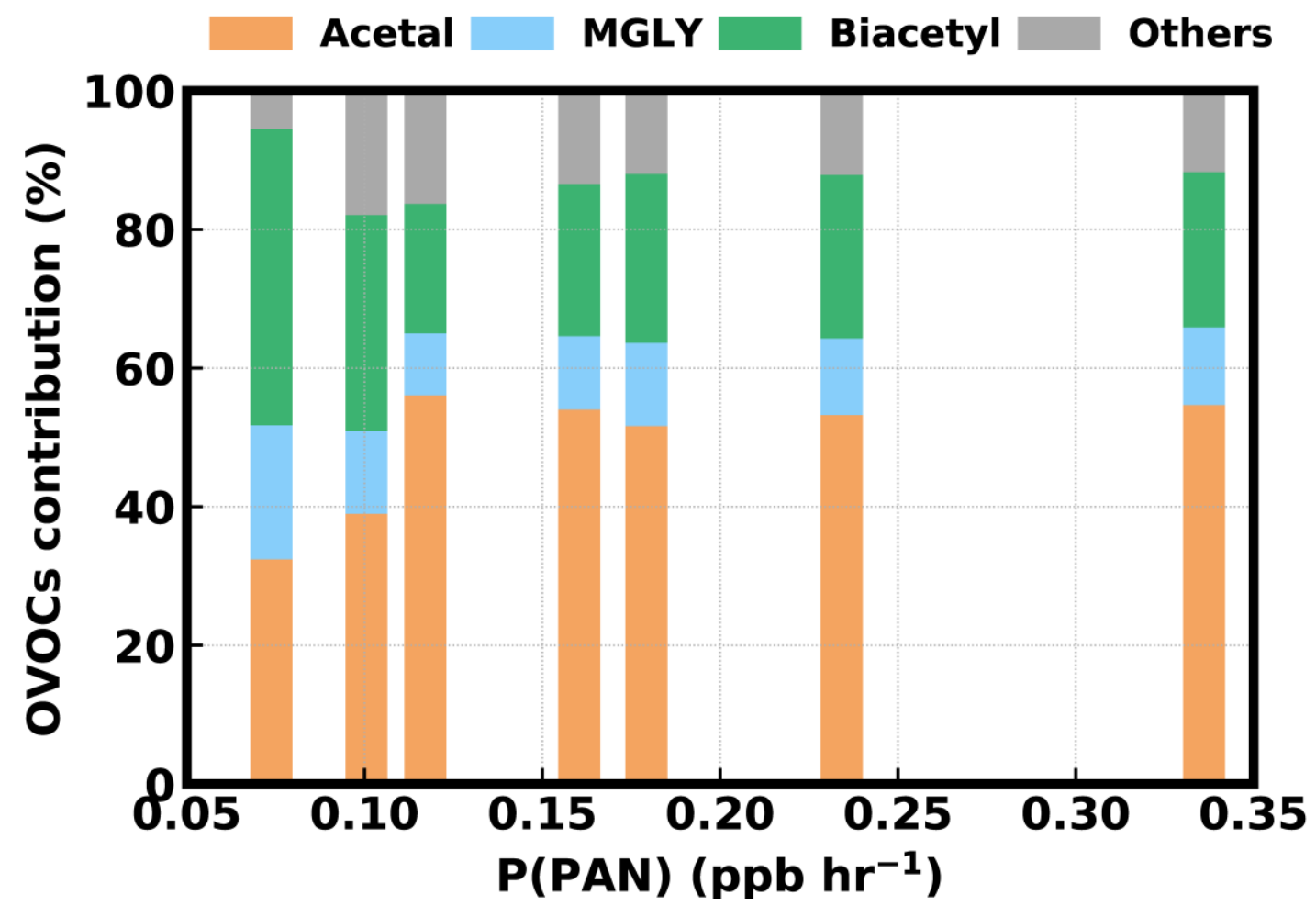

131 Figure S4 Variation of the relative contribution of acetaldehyde, methyl glyoxal, biacetyl and

132 other OVOCs to the formation of PA radicals with the daytime PAN formation rate 

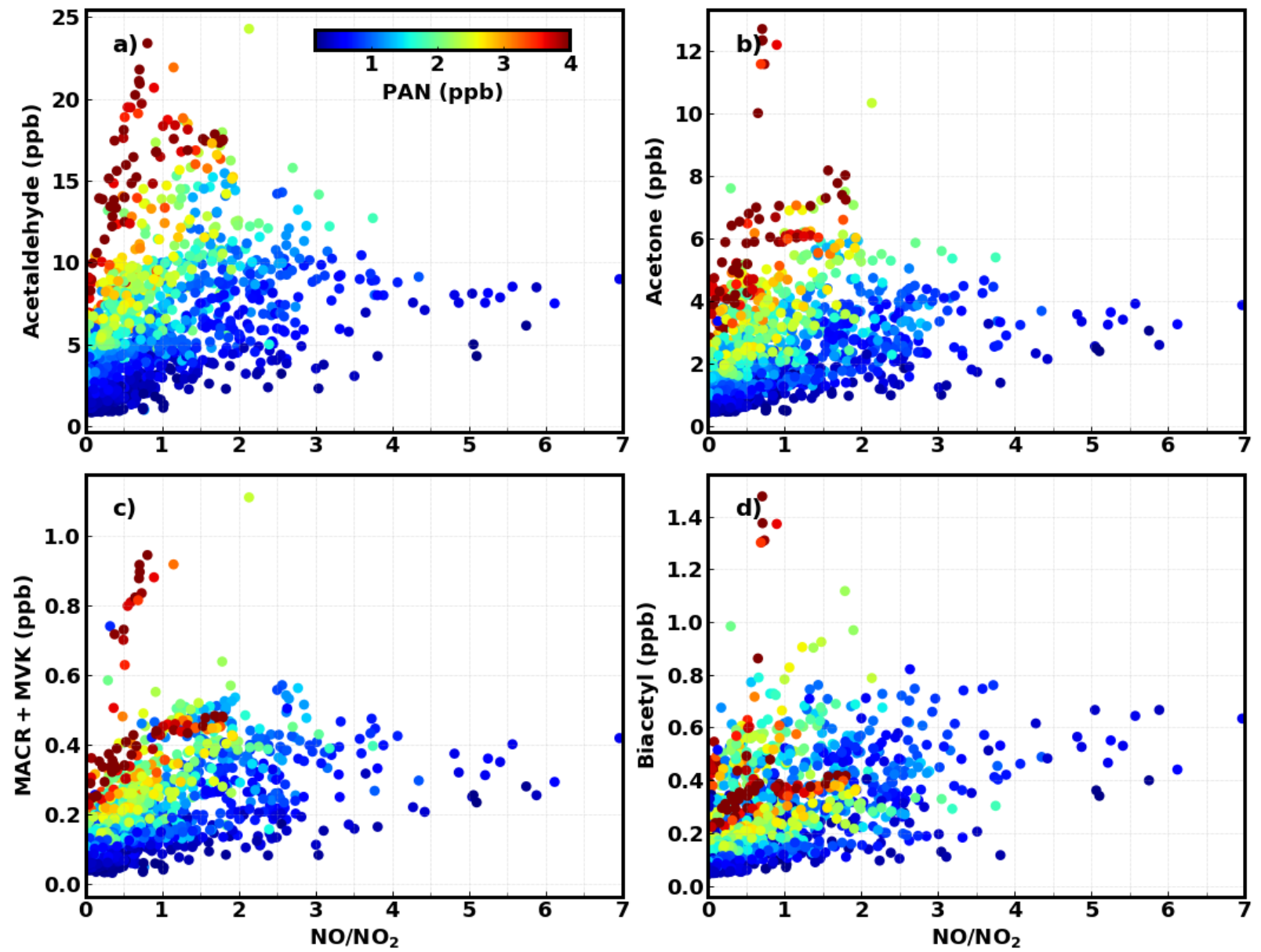

134

135

136

137

Figure S5 Variation of PAN with $\mathrm{NO} / \mathrm{NO}_{2}$ ratio and a) acetaldehyde, b) acetone, c) $\mathrm{MACR}+\mathrm{MVK}$ and d) biacetyl during the entire campaign. 


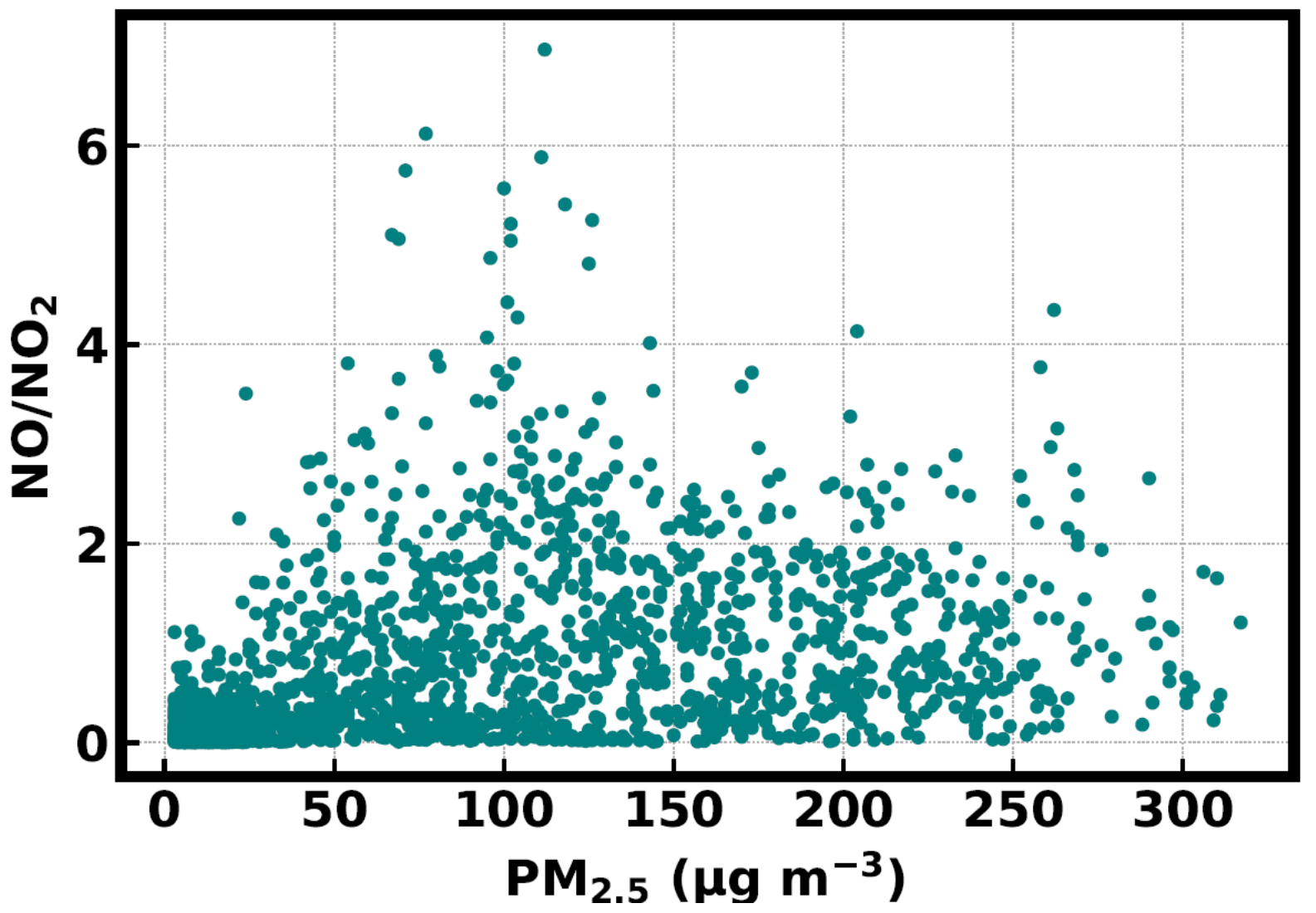

Figure S6. Correlation between $\mathrm{PM}_{2.5}$ and $\mathrm{NO} / \mathrm{NO}_{2}$ during Nov. 2016-Jan. 2017 observed at the Chinese Academy of Meteorological Sciences, Beijing, China. 


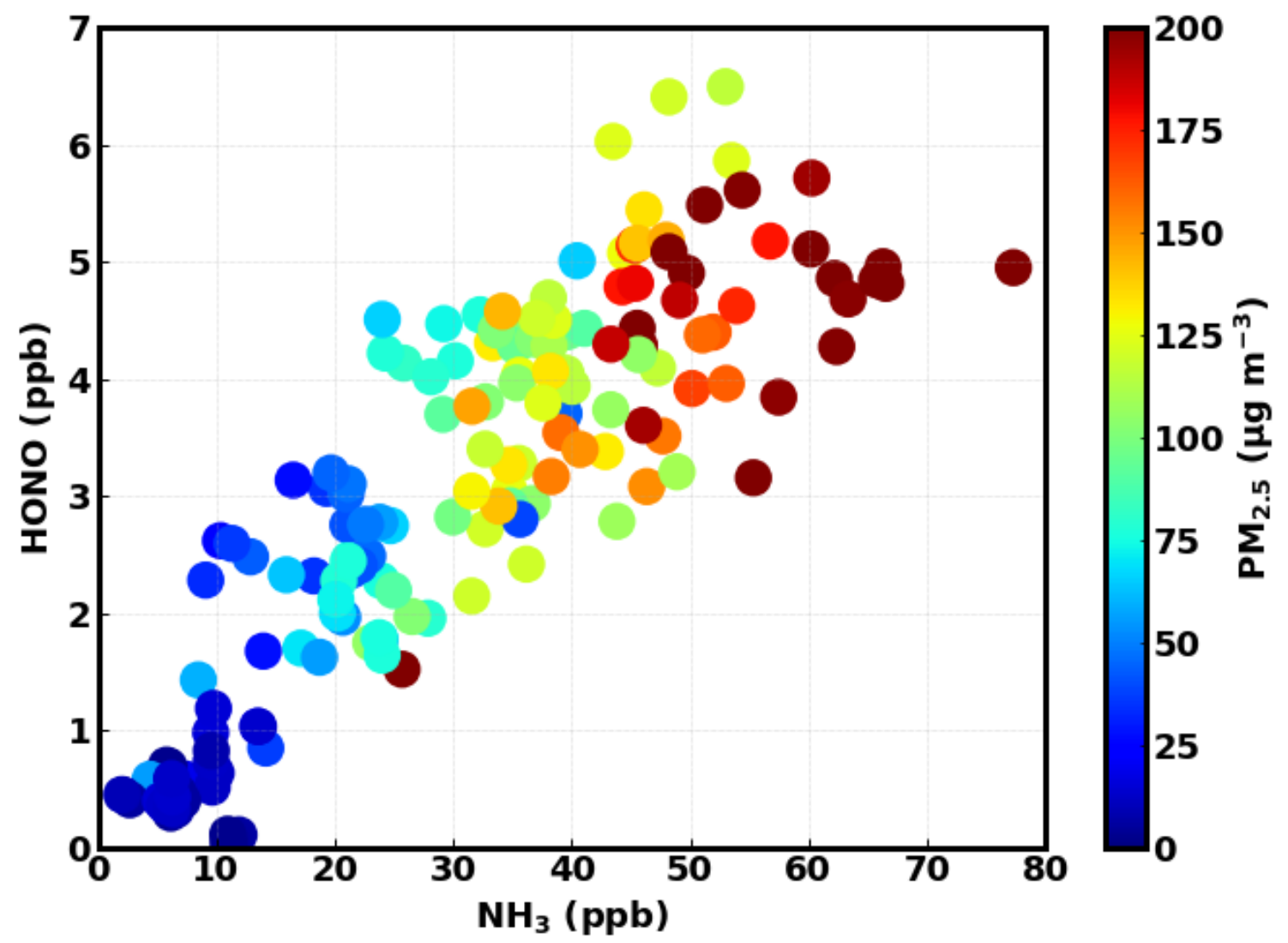

142

143

144 145

Figure S7. Correlations between nighttime $\mathrm{HONO}, \mathrm{NH}_{3}$ and $\mathrm{PM}_{2.5}$ during 10 Nov.-24 Dec. 2016 in urban Beijing 


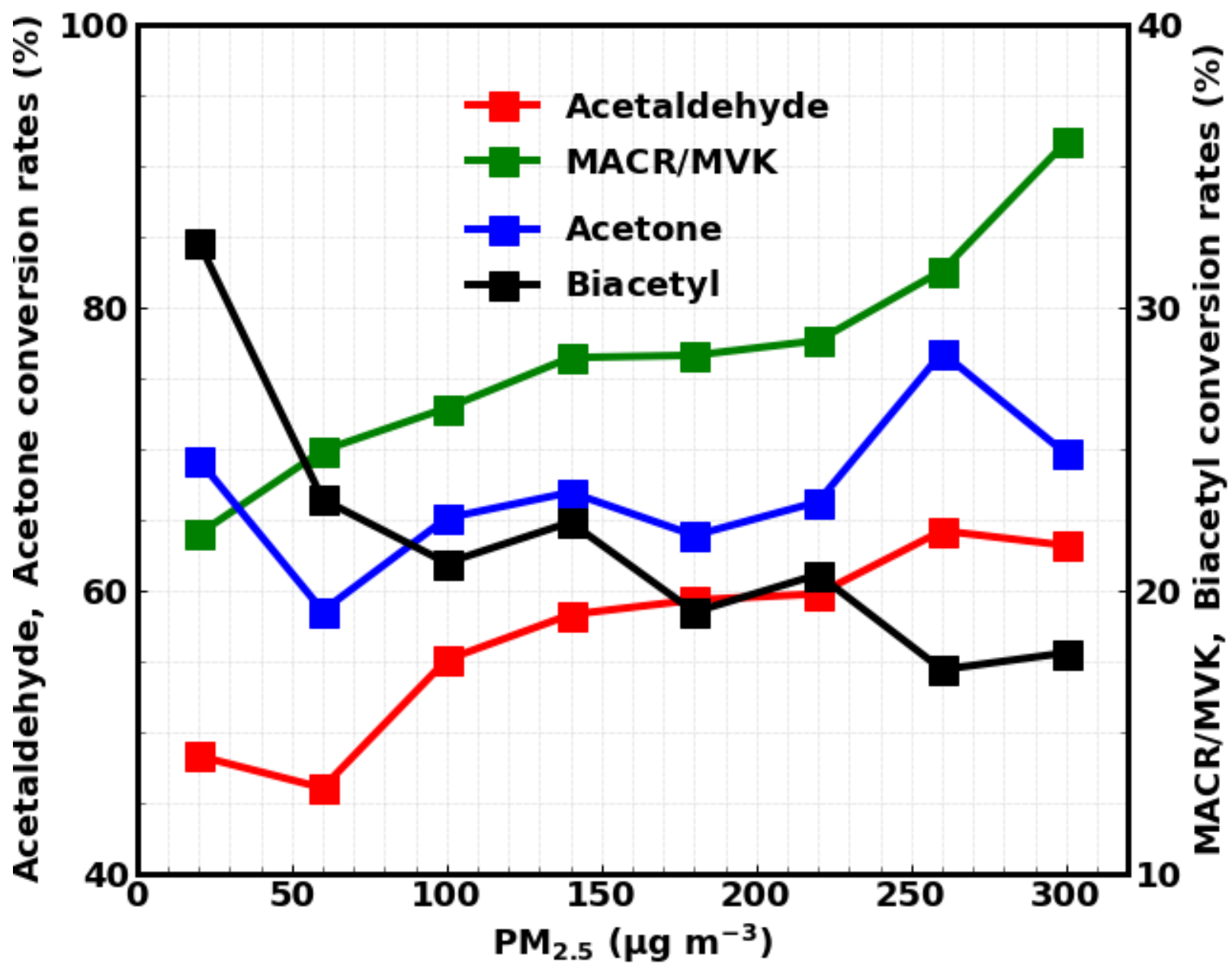

149

Figure S8. Variation of acetaldehyde, acetone, MACR + MVK and biacetyl conversion rates with $\mathrm{PM}_{2.5}$ concentrations during $\mathrm{P} 2$. 


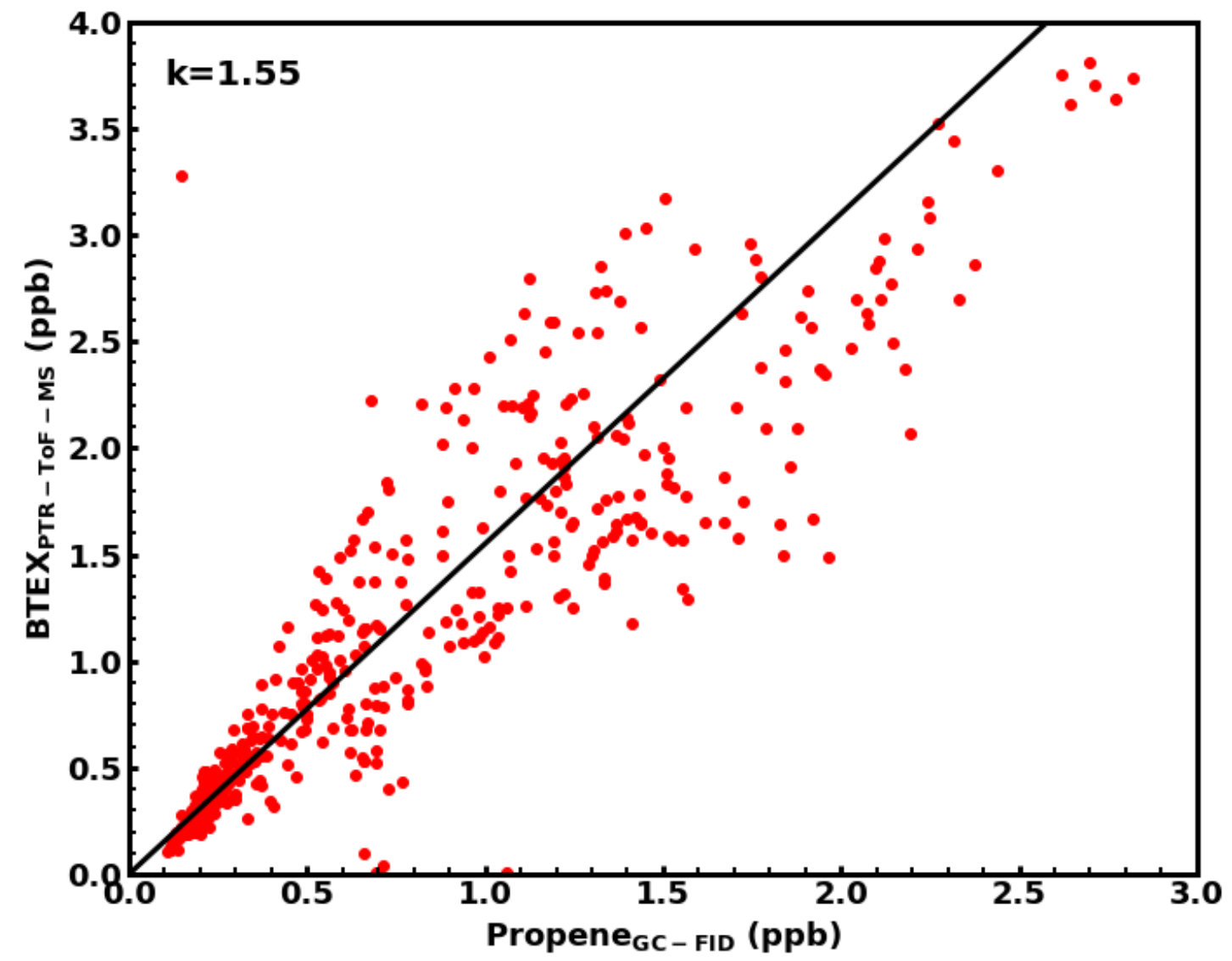

Figure S9. Correlation between BTEX measured by PTR-TOF-MS and propene measured by an GC-FID instrument measured during 19 Jan. to 11 Feb. 2017 (Supplementary methods Sect1.1) 


\section{References}

1. Wolfe, G. M.; Marvin, M. R.; Roberts, S. J.; Travis, K. R.; Liao, J., The Framework for 0-D Atmospheric Modeling (F0AM) v3.1. Geosci. Model Dev. 2016, 9, (9), 3309-3319.

2. $\quad \mathrm{Xu}, \mathrm{W} . ;$ Kuang, Y.; Zhao, C.; Tao, J.; Zhao, G.; Bian, Y.; Yang, W.; Yu, Y.; Shen, C.; Liang, L.; Zhang, G.; Lin, W.; Xu, X., NH3-promoted hydrolysis of NO2 induces explosive growth in HONO. Atmos. Chem. Phys. 2019, 19, (16), 10557-10570.

3. Ye, C.; Zhang, N.; Gao, H.; Zhou, X., Photolysis of Particulate Nitrate as a Source of HONO and NOx. Environmental Science \& Technology 2017, 51, (12), 6849-6856.

4. Xue, L. K.; Wang, T.; Gao, J.; Ding, A. J.; Zhou, X. H.; Blake, D. R.; Wang, X. F.; Saunders, S. M.; Fan, S. J.; Zuo, H. C.; Zhang, Q. Z.; Wang, W. X., Ground-level ozone in four Chinese cities: precursors, regional transport and heterogeneous processes. Atmos. Chem. Phys. 2014, 14, (23), 13175-13188.

5. Vogel, B.; Vogel, H.; Kleffmann, J.; Kurtenbach, R., Measured and simulated vertical profiles of nitrous acid-Part II. Model simulations and indications for a photolytic source. Atmospheric Environment 2003, 37, (21), 2957-2966.

6. Petters, M. D.; Kreidenweis, S. M., A single parameter representation of hygroscopic growth and cloud condensation nucleus activity. Atmos. Chem. Phys. 2007, 7, (8), 1961-1971. 7. Kuang, Y.; Tao, J.; Xu, W.; Yu, Y.; Zhao, G.; Shen, C.; Bian, Y.; Zhao, C., Calculating ambient aerosol surface area concentrations using aerosol light scattering enhancement measurements. Atmospheric Environment 2019, 216, 116919. 8. $\quad$ Ge, S.; Wang, G.; Zhang, S.; Li, D.; Xie, Y.; Wu, C.; Yuan, Q.; Chen, J.; Zhang, H., Abundant $\mathrm{NH}_{3}$ in China Enhances Atmospheric HONO Production by Promoting the Heterogeneous Reaction of $\mathrm{SO}_{2}$ with $\mathrm{NO}_{2}$. Environmental Science \& Technology 2019, 53, (24), 14339-14347.

9. Atkinson, R.; Baulch, D. L.; Cox, R. A.; Crowley, J. N.; Hampson, R. F.; Hynes, R. G.; Jenkin, M. E.; Rossi, M. J.; Troe, J.; Subcommittee, I., Evaluated kinetic and photochemical data for atmospheric chemistry: Volume II -gas phase reactions of organic species. Atmos. Chem. Phys. 2006, 6, (11), 3625-4055.

10. LaFranchi, B. W.; Wolfe, G. M.; Thornton, J. A.; Harrold, S. A.; Browne, E. C.; Min, K. E.; Wooldridge, P. J.; Gilman, J. B.; Kuster, W. C.; Goldan, P. D.; de Gouw, J. A.; McKay, M.; Goldstein, A. H.; Ren, X.; Mao, J.; Cohen, R. C., Closing the peroxy acetyl nitrate budget: observations of acyl peroxy nitrates (PAN, PPN, and MPAN) during BEARPEX 2007. Atmos. Chem. Phys. 2009, 9, (19), 7623-7641. 